Research Article

www.jestr.org

\title{
Factors Effecting Studies in the Department of Industrial Informatics of the Kavala Institute of Technology
}

\author{
P. Polychronidou, I. Petasakis and V. Tsiantos \\ Accountancy Department, Information Management Department, General Department \\ Eastern Macedonia and Thrace Institute of Technology, Kavala, Greece
}

Received 8 July 2013; Accepted 16 December 2013

\begin{abstract}
Information regarding students' and education institutes' progress is a barometer for the overall prestige of the education system in Greece. Scientific community, the relative ministries and the society demand the evaluation of students and education institutes. Higher education studies are one of the most important level of education in Greece and compose important time in the lives of young scientists. A long deliberation took place during the last years regarding the time that is consuming for higher education and whether it should be unlimited or it should be limited to an upper limit. Recently, a rule of $(2 v+1)$ for the upper limit of studies has been set by the Greek state. The pass-mark of 10 has been abolished and a deliberation for possible integration and abolishment of departments has started. In this paper, we study data regarding duration of studies in the department of Industrial Informatics of the Kavala Institute of Technology. The goal of this study is to extract important conclusions for the students' progress and for their evaluation for the department. The final conclusions can become an important tool for the department, in order to make the necessary actions for its better function.
\end{abstract}

Keywords: factors, studies, origin

\section{Introduction}

Institutions of higher education in Greece have always been facing increasing demands by the legislators and the scientific community of the country, who demand valuable information for the students' progress and for the overall prestige of the education system. Except the education conveyors who are obliged to evaluate the institutions, the government through the relative ministries desires to have full access to the aforementioned conclusions (see, 1, 2).

In this paper, a statistical analysis is realized for the Industrial Informatics (II) department of the Kavala Institute of Technology. Several techniques of multivariate analysis (see 3,4$)$ are used in order to detect correlations between factors that affect the duration of studies and the bachelor degree of the graduates. The students' and the graduates' characteristics are described. General data regarding duration of studies for the II department are studied. For the purpose of this study, data were collected by the secretariat office of the department in April of 2010. In total, data were collected for 2675 students who have been registered in the department from 1999 to 2010 . Moreover, with the use of a questionnaire addressed to active students of the department, their evaluation for courses, professors and students is studied.

The goal of this study is to study how many of the

*E-mail address: polychr@teikav.edu.gr

ISSN: 1791-2377 @ 2013 Kavala Institute of Technology. All rights reserved. registered students graduate, how long is the duration of studies, how many overcome the upper limit that the state has set, how many and why are deleted and whether the above are effected by factors such as the semester of each student is at, sex, origin and the way of each student has registered to the department.

\section{Data analysis of the Industrial Information Department}

For the purposes of this study, data were collected by the secretariat office of the department in April 2010. In total, data were collected for the 2675 registered' students from 1999 to 2010. For each student sex, origin, registration year, way of insertion, semester of insertion (registrations used to took place in winter and spring semester as well) have been recorded. Moreover, for each student has been recorded if he/she is deleted and why, if he/she is active of in suspension and if he/she has graduated. For those who have graduated, the year of graduation, the duration of studies and the bachelor degree have been recorded.

In Table 1 the frequency and the percentages of all students from 1999 to 2009 are presented. The biggest percent of $34 \%$ of the students are active, from which $64 \%$ are male and $36 \%$ are female. $31 \%$ have asked to be deleted by the department for several reasons. $16 \%$ of registered students have graduated. $12 \%$ are close to graduate and they have overcome 8 semesters, while $7 \%$ are "stagnates" students. 
Table 1. Registered students per sex

\begin{tabular}{l|c|c|c|c}
\hline & \multicolumn{2}{|c|}{ SEX } & TOTAL & $\begin{array}{c}\% \\
\text { REGISTERED }\end{array}$ \\
\hline & MALE & FEMALE & & \\
ACTIVE & 572 & 327 & 899 & $33.60 \%$ \\
NON ACTIVE & $63.63 \%$ & $36.37 \%$ & & \\
GRADUATES & 2 & 0 & 2 & $100 \%$ \\
& $100 \%$ & $0 \%$ & & \\
DELETED & 273 & 165 & 438 & $16.38 \%$ \\
CLOSE TO & $62.33 \%$ & $37.67 \%$ & & \\
GRADUATE & 537 & 284 & 821 & $30.69 \%$ \\
SUSPENSION & $24.41 \%$ & $34.59 \%$ & & \\
& $79.00 \%$ & $21.00 \%$ & 315 & $11.78 \%$ \\
STAGNATES & $60.00 \%$ & $40.00 \%$ & 5 & $0.19 \%$ \\
TOTAL & 153 & $42 \%$ & 195 & $7.29 \%$ \\
\hline & $78.46 \%$ & $21.54 \%$ & & \\
& 1787 & 886 & 2675 & $100.00 \%$ \\
\hline
\end{tabular}

Regarding the registration year, it is noticed that the number of registrations varies. From 2009 and after there is an important decrease of registrations, because of the passmark of 10. In Table 2 the registrations, deletions and graduations per year of registration are presented. From those who have registered at 2008-2009, almost half have been deleted. The academic year 2007-2008 the percentage of deletions has been decreased to $25 \%$. From those who have registered in $1999-2000$, almost $52 \%$ have graduated, while from those who have registered since then, a gradual decrease is noticed; it is remarkable that for 2004-2005 the relevant percent is at $4 \%$. This happens because only a few graduate in 4 years of studies.

Table 2. Registered, deleted and graduates per academic year

\begin{tabular}{c|c|c|c}
\hline Academic Year & Registered & Deleted & Graduates \\
\hline $1999-2000$ & 216 & 81 & 112 \\
$2000-2001$ & 292 & 112 & 124 \\
$2001-2002$ & 277 & 89 & 93 \\
$2002-2003$ & 308 & 91 & 75 \\
$2003-2004$ & 291 & 91 & 24 \\
$2004-2005$ & 293 & 89 & 10 \\
$2005-2006$ & 301 & 96 & 0 \\
$2006-2007$ & 199 & 72 & 0 \\
$2007-2008$ & 293 & 76 & 0 \\
$2008-2009$ & 132 & 86 & 0 \\
$2009-2010$ & 73 & 1 & 0 \\
\hline
\end{tabular}

Regarding the semester in which each student is, most of them are at the first 5 semesters and in the twelfth, while a gradual decrease of students is realized as long as semesters are passing. Regarding the way of insertion (Table 3), most of the students are registered through the general lyceum exams $76 \%$, while there are registered students through classification exams or through transfers from other departments in Greece.

Table 3. Registered students and way of insertion

\begin{tabular}{c|c|c}
\hline WAY OF INSERTION & TOTAL & $\mathbf{\%}$ \\
\hline GENERAL LYCEUM EXAMS & 2026 & 75.74 \\
NOT FILL IN & 14 & 0.52 \\
VOCATIONAL SCHOOL EXAMS & 439 & 16.41 \\
NIGHT GENERAL LYCEUM & 9 & 0.34 \\
NIGHT VOCATIONAL SCHOOL & 4 & 0.15 \\
SPECIAL CATEGORY (for example, & & \\
athletes) & 104 & 3.89 \\
CLASSIFICATION EXAMS & 75 & 2.8 \\
TRANSFERS & 4 & 0.15 \\
TOTAL & 2675 & 100 \\
\hline
\end{tabular}

Regarding the registration year, male are more than female in both semesters, especially in winter one. Regarding the registered students per year, it is noticed that from 2000 to 2005 and in 2007 there is a steady number of 300 registered students per year, while a gradual decrease is noticed for the rest of the years.

Regarding the way of insertion and the origin (Figure 1) of the students there is a geographical guarantee of preference from students origin from near-by areas $(60 \%)$; also, there is a preference from students origin from the prefecture of Attiki, because of its big population (one out of five students).

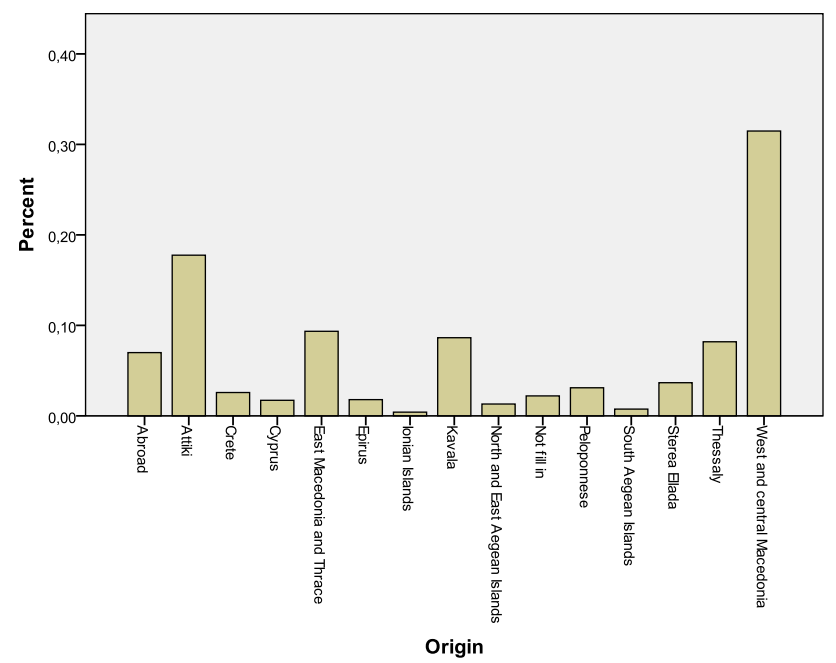

Fig. 1. Origin

Regarding the origin of registered students, almost half come from Macedonia and Thrace regions, $17.6 \%$ from Attiki and the rest origin from other areas of Greece (Table 4). From the prefecture of Kavala origins $8.6 \%$ of the students, $10 \%$ of active students and only $8 \%$ of the deleted students. The biggest percent of the deleted students $20 \%$ origin from Attiki, probably because of the long distance or the transfer to another department.

Table 4. Origin of students and status of studies

\begin{tabular}{lccc}
\hline \multicolumn{1}{c}{ Origin } & Registered & Active & Deleted \\
\hline Kavala & 231 & 142 & 65 \\
East Macedonia and Thrace & 250 & 152 & 165 \\
West and central Macedonia & 842 & 489 & 208 \\
North and East Aegean & & & \\
Islands & 35 & 17 & 12 \\
Peloponnese & 83 & 40 & 22 \\
Sterea Ellada & 98 & 36 & 39 \\
Epirus & 48 & 20 & 15 \\
Thessaly & 219 & 107 & 79 \\
Attiki & 475 & 221 & 165 \\
South Aegean Islands & 20 & 13 & 4 \\
Ionian Islands & 11 & 3 & 6 \\
Crete & 69 & 22 & 39 \\
Cyprus & 46 & 19 & 19 \\
Abroad & 187 & 101 & 58 \\
Not fill in & 59 & 30 & 29 \\
TO TAL & 2675 & 1412 & 825 \\
\hline
\end{tabular}

Furthermore, for deletion reasons, it is noticed that the main reason is not registering at the next semester $35.6 \%$, while the insertion to another department is at $27.55 \% .22 \%$ of the students who apply to be deleted origin from Attiki, while $25.6 \%$ of the students who are inserted to another department origin from central and west Macedonia. 
Most of the students graduate in 6 or 7 years, while those who graduate in 9 or 10 years are a few. It is noticed that during the years 2007-2008 and 2008-2009 there are the most graduations of all years (505 graduates). The fewest graduations have been realized in 2003-2005.

Regarding the duration of studies of the graduates (Figure 2), it is noticed that only $1-3 \%$ of the registered students graduate in 4 years of studies. Most of the students who have been the first to register in the II department graduated in 4 to 5 years in opposition to the majority of students who graduate in 7 years.

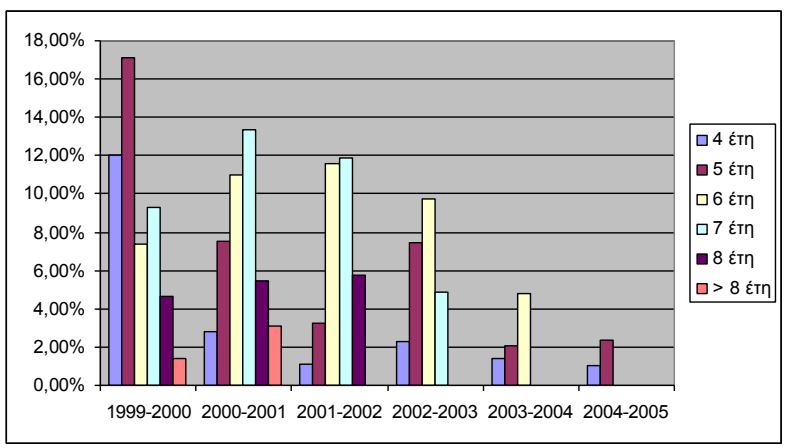

Fig. 2. Graduates per duration of studies

Regarding the bachelor degree, it is noticed that there is a width from 6 to 9 and the average is located low. From the data analysis regarding the selection of the department and the degree correlated with the sex, it is found that the average selection for male is the $66^{\text {th }}$, while for female is the $82^{\text {th }}$ and that the average bachelor degree is 6.6 for male and 6.53 for female. Students that have been registered in 2000-2001 have the lowest degree; male (6.51) and female (6.52). The highest degree is for male who have registered in 2004-2005 with 6.83 and for female in 2003-2004 with 6.84 .

\section{Empirical research}

With the use of a questionnaire addressed to active students of the department, their evaluation for courses, professors and students is studied. It was distributed in October of 2010 and the number of students that have responded is 106 . The statistical analysis was realized with the statistical package SPSS 17 (Statistical Package for the Social Sciences).

From the descriptive statistic analysis, male are $66 \%$ of the sample and female are $34 \%$. The biggest mass of the sample origin from west and central Macedonia 35.8\%. Almost $60 \%$ origin form near-by areas. Regarding students' secondary education, the majority of them come from Lyceum at $80 \%$. From the possible education directions in secondary school, $52.8 \%$ chose technological, $18.9 \%$ informatics and $16 \%$ theoretical. Finally, $42.5 \%$ responded that the II department was one of the top selections for departments, while even more responded that it just happened.

The average semester of the respondents is the $8^{\text {th }}$, while there are students at the $19^{\text {th }}$ semester. The average number of passed courses is 18 . Regarding the evaluation of the education process, almost $54 \%$ attend to all courses, $11.4 \%$ do not attend courses and $35 \%$ behave neutral.

Almost $11.5 \%$ study and work on paper outside university campus in weekly basis, $30 \%$ do not study at all and the rest give their attention to studying in a moderate degree. Regarding the clarity and the material of courses the respondents evaluate them mediate $62.3 \%$, very positive $16 \%$ and very negative $21.7 \%$. At the question if there is connection of courses, the respondents evaluates it below average at $72.4 \%$. Regarding the evaluation of courses and the educational material almost $54,7 \%$ evaluate them moderately, $16 \%$ positive and $29.2 \%$ negative. Regarding the professors' evaluation, $63.2 \%$ evaluates them mediate, while positive and negative percentages to be at $18 \%$ each. At the question whether professors manage to stimulate the interest of the students, $84 \%$ believe that the professors perform mediate and low, while only $16 \%$ evaluate them positive. Regarding the encouragement for questions, the evaluation are whipsawed with a small prevalence of positive. Similarly, in whether professors answer to questions of students, there is a tension towards positive evaluation, with the above mediate percentages to be at $82 \%$. At the question if the courses have enriched the students' knowledge, $46.2 \%$ are satisfied and $12.3 \%$ are not. Regarding the use of the courses, $40.6 \%$ evaluates it positive and $33 \%$ evaluates it as mediate.

Regarding the satisfaction from the overall personal view of the students, $82.9 \%$ is under mediate. Especially, the evaluation on the satisfaction from the professors is under mediate at $85.8 \%$. Regarding the evaluation of the secretariat support the vies are diverged. However, there is a tension for the negative evaluations with the under mediate replies to be at $72 \%$. Regarding the evaluation of the technical and material accoutrements, again the evaluations are under mediate to negative at $77 \%$. Finally, regarding the interest of occupation with the scope of studies, the majority of the students are positive at $70 \%$. Regarding the easy of finding work relative to the scope of studies, students are not optimistic, with the negative tension to be at $80 \%$.

Analyzing the data regarding the separation of the sample, men choose the II department more wittingly $45.75 \%$ than $36.1 \%$ women. The majority of women come from lyceum and only few from occupational school. The same percentages stand for men with small alterations. Both men and women attend lectures at $40 \%$ and $47.2 \%$, respectively. Regarding the weekly study, both men and women correspond mediate. Regarding the evaluation of organizing the courses' content and the educational material, women evaluate them more positive than men. Regarding the professors' evaluation, women are more positive than men, with the mediate choice to be at $86.1 \%$, while for men to be at $78.6 \%$. regarding the possible interest in working in informatics, women are less positive than men with the mediate and very options to be at $86 \%$, while for men to be at $97 \%$. Regarding the easy at finding an occupation in informatics, there is the same tension as above.

Besides students origin from Kavala, Sterea Ellada, Epirus and abroad, students from all other regions attend almost all lectures. Students from occupational schools attend lectures more than students from general lyceum. Regarding the weekly studying, students from lyceum study more than students from occupational schools. Moreover, students from positive direction in lyceum, have passed 23 courses in average. From the ratio of courses and semester, there are the following remarks regarding the direction of studies in lyceum: technological 2.07 lessons per semester, informatics with 2.42 , positive with 2.45 and theoretical with 2.24. Regarding the past courses per semester, it is noted that students at the $4^{\text {th }}$ and $5^{\text {th }}$ semesters have the best performance. The oldest the semester, the worst the performance. Finally, students who chose the II department 
have better performance than students who did not wanted so much the department.

\section{Conclusions}

Concluding and summarizing the results, the main elements are the following:

- There is a step-by-step reduction of registrations, with the peak at the academic year 2009-2010, where the registered students were the fewest of the decade because of the base of ten.

- The highest percentage of students are active, $64 \%$ men and $36 \%$ women. $31 \%$ have asked to be deleted for several reasons.

- Only $16 \%$ of registered have graduated, while $12 \%$

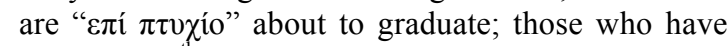
passed the $8^{\text {th }}$ semester of their studies.

- Almost half origin from Macedonia an Thrace regions, while the biggest percentage of deleted students origin from Attiki region.

- The majority come from general lyceum, with the main reason to be the scientific subject of the department.

- From the students registered at the first years of the II department, the majority of them have graduated, while from those who have registered later, there is a gradual reduction, because only a few graduate in four years.

- The majority of students graduate in 6 to 7 years.

- The average bachelor degree for men and women is the same, not higher than 7 .
- Regarding the reason for deletion, the main is the non continuation in registering at every semester, with the transfer in another department being the second reason.

- The highest percentages of deleting students come from central and west Macedonia and Attiki regions.

- The main reason of deletion is the application of the student, especially origin from Attiki region.

In general, the way of teaching must be elevated, in order for courses to be accessible and useful for students. It must be clear that the total of courses must be useful tools of understating and solving problems in the relative science. In this study, the overall view of structure and function of the department has been impressed, in order to reform the program of studies, to use modern ways of teaching and to train the professor towards that direction. Also, the reorganizing of the material of basic courses must be considered, in order for the transmission from secondary education to higher to be as smooth as possible; giving emphasis in covering basic misunderstandings and ignorance in knowledge of the new students.

Moreover, it must be pointed out that the above are speculations of the Kavala Institute of Technology and the overall of the education institutes in Greece. Thus, it is necessary to create a network of professors of all coherent departments, in order to make the relevant debates, suggestions and for the success of the above; it is necessary to train the professors continuously and at the same time, in order for the new methods of education to be applied and their level of knowledge to get better.

\section{References}

1. Amagi, I., 1988, Educational reform in international perspective, International Journal of Educational Research, 12, 2, 103-226.

2. Berkner, L, and Choy, S., 2008, Descriptive Summary of 2003-04 Beginning Postsecondary Students: Three Years Later, National Center for Education Statistics, Institute of Education Sciences, U.S. Department of Education.

3. Markos, A., Menexes, G. and Papadimitriou, I., 2006, "Factor analysis of correspondences through C.HI.C. Analysis software," Proceedings of the 19th Panhellenic Statistical Conference (in Greek).

4. Papadimitriou I., 2007, "Data Analysis", ed. Tipothito, Athens (in Greek). 